\title{
"With an LD you're always mediocre and expect to be mediocre": Perceptions of Adults Recently Diagnosed with Learning Disabilities
}

\author{
Cheryll Duquette and Stephanie Fullarton \\ University of Ottawa
}

\begin{abstract}
The purpose of this qualitative study was to examine the educational and employment experiences of 10 adults who had recently been diagnosed as having a learning disability. Seven of the participants eventually obtained a high school diploma or the equivalent and they all had held a variety of entry-level jobs. The participants felt that having an undiagnosed learning disability had negatively affected their past, present, and future educational and employment opportunities. The importance of a caring adult to advocate on behalf of at-risk students and a set of goals, skills, and abilities that should be developed while in school emerged from the findings.
\end{abstract}

Learning disabilities (LD) refers to a number of disorders that may affect the acquisition, organization, retention, and understanding or use of verbal or nonverbal information. These disorders affect learning in individuals who otherwise demonstrate at least average abilities essential for thinking and/or reasoning and are distinct from global intellectual deficiency (Learning Disabilities Association of Canada, 2002). A person with LD has average to above average intelligence, but generally experiences lower academic performance and possibly social and emotional problems (Wong, 1996). In Canada, approximately half of all students identified as having an exceptionality have LD (Friend, Bursuck, \& Hutchinson, 1998). Differences in definitions and inconsistent identification procedures influence Canadian estimates, which suggest that $2-4 \%$ of the school-age population has LD (Hutchinson, 2007).

\section{Perspectives}

In recent years, there has been an interest in the post-school outcomes of adults with disabilities, and in particular, those with LD (Lindstrom \& Benz, 2002; Litner, Mann-Feder, 
Guérard, 2005). Research has focused on two main areas: postsecondary education and employment.

Postsecondary education. Participation rates in postsecondary programs after the first 3 years out of school among adults with disabilities are lower than among those without disabilities (26.7\% vs. 68\%, respectively; Blackorby \& Wagner, 1996). Factors linked to successful educational outcomes among students with disabilities include participation in transition planning during high school; student satisfaction with high school instruction; appropriate instruction and good performance in reading, writing, math, and problem-solving; and getting along with people (Halpern, Yovanoff, Doren, \& Benz, 1995).

It has been noted that participation in postsecondary courses among adults with LD is generally difficult because of the lack of preparation for college coursework and the varied levels of support available in postsecondary institutions (Halpern et al., 1995). However, some persist and achieve positive outcomes. Students with LD who do graduate from postsecondary institutions have developed compensatory strategies (e.g., word processors, books on tape), personal learning strategies, and executive functions (e.g., time management, metacognition, setting work priorities; Litner et al., 2005; Reis, Neu, \& McGuire, 1997). Additionally, they had the drive to succeed and were engaged in self-advocacy (Fullarton, 2006; Litner et al., 2005). Graduates with LD also reported that they had support networks consisting of family, friends, academic (e.g., secretarial, tutors), and mentors (Fullarton, 2006; Reis et al., 1997).

Employment. Blackorby and Wagner (1996) found that 3 to 5 years after high school graduation $57 \%$ of students with disabilities were employed compared to $67 \%$ of their peers without disabilities. Those who graduated from high school were more likely to be employed than those who withdrew. During their first 2 years of employment the wages were low, but appeared to rise over time - if they were able to keep their jobs. The transition from high school to employment among adults with LD appears to be linked to a number of factors. Lindstrom and Benz (2002) developed a framework for understanding the transition process that takes into account internal and external factors. They interviewed six young women who had LD and identified three phases of transition: unsettled, exploratory, and focused. The young women in the unsettled group were in conflict with their parents over career goals: They took employment that was accessible and demonstrated inconsistent work habits; they lacked motivation and were sidetracked by their personal lives; and when they were not prepared to meet the demands of holding a job, they were let go or quit. This group also experienced a lower level of support and flexibility from employers. The young women in the exploratory stage had a steady job, but were struggling to find a career direction; however, unlike those in the unsettled phase, they had support from their family and employers, and high expectations for success. The young women in the focused group had decided on a career goal before graduating from high school, enjoyed the support of family and employers, and had a mentor beginning in high school.

Over the long term, research has shown that adults with LD are likely to experience unemployment or underemployment (Fourqurean, Meisgeir, Swank, \& Williams, 1991), and the vast majority are employed in entry-level, base-wage positions (Mellard, 1996). As well, employers are not prepared for employees with LD, and people with LD neither self-disclose nor seek accommodations (Lindstrom, Doran, Metheny, Johnson, \& Zanc, 2007; Price \& Gerber, 2001; Price, Gerber, \& Mulligan, 2003).

The predictors of career success among older adults with LD are related to other factors. 
Researchers have identified specific internal factors, such as a desire to succeed, goal orientation, and reframing, that contribute to career success (Gerber, Ginsberg, \& Reiff, 1992). Other internal factors that play a role in the career outcomes of adults with LD include learned creativity (coping strategies), self-awareness, proactivity, perseverance, emotional stability, and appropriate goal-setting (Raskind, Goldberg, Higgins, \& Herman, 1999). External factors linked to career success among adults with LD are the goodness of fit between the job and their strengths and weaknesses, social ecologies (supportive people), and the use of effective support systems (Raskind et al., 1999). A notable characteristic missing from this list is IQ; it was found not to be a powerful predictor of career success.

Another study on the development of individuals with LD over many years also found no evidence of a link between IQ and career success. In a longitudinal study of individuals at risk that began in 1955, Werner and Smith (2001) traced the life outcomes of 22 individuals (of a cohort of 129) living in Hawaii, who had been diagnosed by age 10 with LD. During adolescence, this sub-group experienced poor scholastic performance and serious underachievement. However, by age 40 one-half had obtained additional education after high school and not one was unemployed or relied on welfare payments. The majority worked in service jobs or as skilled technicians. The authors noted five protective factors that affected resilience: temperament, special skills and realistic vocational plans, caregiving styles of their mothers (nurtured self-esteem), supportive adults, and openings or opportunities at major life transitions (e.g., from high school to the workplace). These protective factors contributed to the ability of the participants with LD to recover from their previously at-risk status.

The previous studies found internal and external factors that contributed to positive career outcomes; however, other research has found factors linked to negative outcomes, such as unforeseen occurrences. Rojewski (1999) reported that individuals with LD have lower career maturity and career aspirations, an external locus of control, academic difficulties, and problems with reasoning or decision-making, which makes the role of chance more important in their lives than for adults without LD. He argued that due to these characteristics, some people with LD may not recognize fortuitous career opportunities when they are presented because they misread cues, display inappropriate behaviour, or have difficulty predicting consequences.

Taken together, these studies suggest that short- and long-term educational and career outcomes of adults with LD are affected by the interplay of three main factors. First, personal characteristics, such as an easy-going temperament, a special talent, a strong desire to succeed, specific and realistic career goals, the ability to recognize potential career opportunities, and the opportunity to develop personal learning/working strategies, contribute to positive outcomes. Second, contextual factors that include the availability of support services and assistive technology, supportive people, and a good fit between the individual's strengths and the academic program or job also play a role. Third, the willingness to accept assistance, advocate for accommodations, and take advantage of the support offered by the environment so that it may be modified to meet the individual's needs also affect academic and employment outcomes.

These protective factors were drawn from studies with people who had been identified as having LD when they were in school. For the most part, they had enjoyed some success in their post-school pursuits, and the researchers studied the reasons for their positive outcomes (Fullarton, 2006; Gerber et al., 1992; Lindstrom \& Benz, 2002; Litner et al., 2005; Werner \& Smith, 2001). Clearly, the participants of these studies had benefited from being identified at a relatively young age. Not all people with LD, however, are identified while in school, and consequently, they do not have the opportunity to enjoy the potential benefits of a range of services and pro- 
grams that are available in schools and postsecondary institutions. It is not unusual for adults with an undiagnosed LD to go through life feeling that they have some abilities, but that their deficiencies present a barrier to career success (Duquette, 2000). The revelation that one has LD may come with a sense of relief, as the person's intuitive understanding of individual strengths is validated and he or she now comprehends why performance on certain tasks has been relatively poor (Duquette, 2000; Litner et al., 2005). However, there is little information on the actual experiences of individuals who were diagnosed as having LD as adults and who did not have the benefit of services and accommodations shown to contribute to academic and employment success. It is not known how an undiagnosed LD affects educational and employment outcomes and the types of programs and services that could be put into place to assist them. Thus, the purpose of the present study is to examine the educational and employment experiences of adults recently identified with LD.

\section{Methodology}

This phenomenological study, which used a collaborative autobiographical approach, explored the educational and employment experiences of adults recently diagnosed with LD from the perspectives of the adults themselves. The focus of this type of research is on determining what the experiences mean to each participant and deriving general meanings from the individual stories (Moustakas, 1994). Pinar and Grumet (1976) suggested four steps in autobiographical research: regression, in which participants look to the past and describe their responses to those situations; progression, in which participants look to their future and discuss where their career may be going; analysis, in which they describe their present biographies; and synthesis, where participants put all three pictures together. Participants using this model usually record in writing their experiences and reflections; however, the adults in this study had deficiencies in written expression. Hence, the researchers assisted them in this process by asking the questions, recording their responses, and providing assistance through prompts with the reflective tasks (e.g., How did you react to that? What did you think of that?).

\section{Participants}

Purposeful sampling was used to recruit 10 participants ( 5 men and 5 women) who had recently been diagnosed as having LD. Seven of the participants ( 5 men and 2 women) had just been assessed by a registered psychologist as part of a project funded by the City of Ottawa. A battery of psychological tests was given to people on social assistance who were suspected of having undetected LD. At the end of the debriefing meeting, the psychologist gave them the recruitment notice in which they were asked to contact the principal researcher if interested in participating in this study. The other three women were recruited through the Learning Disability Association of Canada. A notice was sent by e-mail attachment to administrators of their Destination Employment Program who posted it in the adult services offices across the country.

The participants ranged in age from 21-44 years and all were receiving or had received social assistance. Only one had a criminal record for incidents that had occurred years ago: underage drinking, stealing a car, and fighting. More than half of the participants had no health problems that affected their employability. Four of the participants were single and had never 
married, half were single and had previously been in a relationship, and one was married. Three women lived with their children; one man did not seem to have much contact with his children.

\section{Data Collection}

The single source of data was an in-depth, semi-structured interview in which participants were asked questions about themselves, their educational and work experiences, the moral support they received, and goals they had for themselves. The purpose of the interviews was to understand the experiences of the participants and the meaning they made of them. Although it would have been desirable to have a series of three interviews, as proposed by Seidman (2006), it was felt that the participants would not be available, either by choice or circumstance, for more than one interview. Hence, the interviews were conducted within a 90-180 minute period. The 65 items in the interview schedule consisted of closed questions used to obtain demographic information and open-ended items to elicit autobiographical and reflective data (see Appendix). Most questions were written simply and contained only a single idea to reduce ambiguity (Patton, 1990). The interviews were recorded over the telephone, and participants had an opportunity to elaborate on their experiences (Marshall \& Rossman, 2006). The longest interview was conducted on two consecutive days. A transcript of each interview was prepared.

\section{Data Analysis}

The data were read and re-read, then coded into broad categories and further organized into sub-categories (Denzin \& Lincoln, 2000; Mertens, 2005; Miles \& Huberman, 1994). Specifically, when coding, the lead author highlighted significant text, took notes, and wrote comments in the margin. The categories included (a) types of LD, (b) educational experiences, (c) employment experiences, (d) goals, and (e) sources of support. The five categories, shown in Table 1, were developed and refined over the course of analyzing the data. The sub-categories enabled us to know what LD the participants had and to consider how they affected their educational and work experiences, and personal goals. Interpretations were made using inductive reasoning (Miles \& Huberman, 1994; Patton 2002) and the structure of the experience is described (Moustakas, 1994).

Table 1

Coding Categories

\begin{tabular}{ll}
\hline \multicolumn{1}{c}{ Major Category/Code } & \multicolumn{1}{c}{ Subcategory } \\
\hline Types of learning disabilities & Language, math, processing, memory, ADD/ADHD, secondary disabilities \\
Educational experiences & Elementary, secondary, post-secondary \\
Employment experiences & Types of jobs, positive and negative experiences, barriers \\
Personal goals & Types \\
Sources of moral support & While in school, present sources \\
\hline
\end{tabular}




\section{Trustworthiness}

Researchers must establish indictors that provide evidence that the data collected are authentic and believable (Freeman, deMarrais, Preissle, Roulston, \& St. Pierre, 2007). The three indicators used in this study were credibility, transferability, and confirmability. Credibility refers to the correspondence between the researcher's portrayal of the participants' viewpoints and the way the participants actually perceive the phenomena (Mertens, 2005). Guba and Lincoln (1989) stated that member checks are the most important criterion for establishing credibility. Hence, the interview transcripts were sent to the participants to ensure they accurately represented their thoughts and views. Only one participant returned her transcript with additional information about events she had described; the revised transcript was used as a data source. Transferability refers to the degree to which the findings may be generalized (Guba \& Lincoln, 1989). It is the researcher's responsibility to provide enough data so that readers may decide the extent to which the findings may be transferred to their situation. In this case, the lengthy interviews provided sufficient data to permit readers to generalize. Confirmability ensures that data and interpretations can be traced to their original sources; the second author conducted a confirmability audit to ensure that categories and sub-categories could be traced to the interview data.

\section{Findings}

\section{Learning Disabilities}

Each of the participants had recently been diagnosed as having LD. Except for Jason (all names are pseudonyms), this was the first time they had recalled having undergone psychological testing for LD. Almost all of the 10 participants stated that they had dyslexia, more specifically problems with decoding and comprehension (see Table 2). Only Lorna stated that her LD was in math. Additionally, half of the adults stated that they had low scores in spelling, and four had difficulty expressing their thoughts in writing. Many of them also revealed that they had difficulties doing math computation and problems. Three reported problems with auditory processing and memory, and four participants stated that they also had ADD or ADHD. Other difficulties linked to their LD included problems with speaking, organization, sequencing, and eye-hand coordination. Most of the participants also revealed that they had secondary disabilities: anxiety (4 women and 1 man) and depression ( 3 men).

Of their personality traits, Renata, Cameron, and Jason stated that their sense of humour was their best quality, whereas Guillaume and Lorna identified loyalty as their most favourable quality. Jake and Lorna stated that their worst personality trait was organization, and Tammy and Liz reported an inability to focus. For many of the participants, interpersonal skills were a weakness: They explained that they interpreted comments in a negative way and they argued or spoke without thinking, especially when others were being critical of them.

All of the adults suspected that they had a LD. Renata mentioned that others in her immediate family had been diagnosed with LD and consequently was not too surprised at her diagnosis. Holly stated that she had wondered if her problems with spelling, reading, and memory might be linked to LD. Cameron also thought he might have LD because of problems with reversals and interpreting communication. Three other participants commented on how they struggled in school and at work when others did not. All of the adults were aware of differences between them and their peers and suspected LD as the reason for their difficulties. 
Table 2

Demographic Characteristics of the Participants

\begin{tabular}{|c|c|c|c|c|}
\hline Participant & Sex & Age & Learning Disability and Other Diagnosis & $\begin{array}{l}\text { Physical and/or } \\
\text { Psychological Problems }\end{array}$ \\
\hline Renata & $\mathrm{F}$ & 22 & $\begin{array}{l}\text { Sequencing, dyslexia, organizing thoughts on } \\
\text { paper, spelling }\end{array}$ & Injury to hand, anxiety \\
\hline Jake & M & 37 & Dyslexia, spelling, organizing thoughts on paper & Anxiety \\
\hline Cameron & M & 21 & $\begin{array}{l}\text { Dyslexia, spelling, organizing thoughts on paper, } \\
\text { math, memory reversals, processing, ADD }\end{array}$ & Depression \\
\hline David & M & 39 & $\begin{array}{l}\text { Dyslexia, math, verbal-processing, } \\
\text { short-term memory }\end{array}$ & $\begin{array}{l}\text { Arthritis, injury to shoulder, } \\
\text { tennis elbow, depression }\end{array}$ \\
\hline Holly & $\mathrm{F}$ & 44 & $\begin{array}{l}\text { Dyslexia, spelling, eye-to-hand coordination, } \\
\text { math, auditory memory }\end{array}$ & Anxiety \\
\hline Guillaume & M & 40 & Dyslexia, organizing thoughts on paper & $\begin{array}{l}\text { Headaches, back pains, joint } \\
\text { pains, depression }\end{array}$ \\
\hline Jason & M & 23 & Dyslexia, processing information, ADD & \\
\hline Liz & $\mathrm{F}$ & 24 & Dyslexia, math, spelling, ADD & Anxiety \\
\hline Tammy & $\mathrm{F}$ & 32 & $\begin{array}{l}\text { Dyslexia, spelling, math, processing, memory, } \\
\text { focusing }\end{array}$ & Anxiety \\
\hline Lorna & $\mathrm{F}$ & 29 & Math, ADHD & \\
\hline
\end{tabular}

Most of the participants expressed relief that they had a diagnosis because they now understood more about themselves - their strengths and weaknesses and the source of their frustrations. Some also stated that they know what jobs would be a good fit for them. Others commented that they did not feel so "stupid" now that they had a diagnosis of LD, they understood the need for academic accommodations, and they would have to work very hard to achieve average marks in postsecondary studies.

During the interviews, the participants expressed their feelings about having LD. Some stated that having LD was negative. For example, David commented, "I'm still trying to accept it. To me it's a negative thing. It's like I've been stopped, paused." Similarly, Jason said, "I have to try a lot harder and try not to get discouraged when I don't succeed." Jake was neutral in his reaction to having been diagnosed with LD and stated that it meant "nothing." Only Holly expressed positive feelings: "I've learned that I don't have to get so frustrated with myself... knowing allows me to accept what I can't do."

\section{Educational Experiences}

Nine participants were placed in regular education classrooms: five had no assistance and four were withdrawn to the resource room for remedial instruction in math, spelling, and writing. Only Guillaume was schooled mostly in special education classes. Several participants had a 
fairly stable attendance pattern; however, three transferred from school to school. Of these individuals, Renata commented that her family moved once a year and Guillaume stated that he "lived like a gypsy." While in school, another two men confided that they had behavioural problems: Jake acted out and recalled being strapped and Cameron described himself as the class clown. Despite the transience of some and the behavioural problems of others, most of the participants passed each year. However, Jake, Cameron, and Tammy failed one grade (grades 3, 4, and 5 respectively) and all three eventually dropped out of high school.

At the secondary level, half of the participants attended special types of schools. David, Guillaume, and Jason enrolled in a vocational high school; Cameron attended an alternative school; and Lorna was at a high school devoted to the arts. Renata and Holly attended more than three schools and both had also moved frequently in elementary school. Many of the participants told of behaviour and mental health problems while in high school: acting out, skipping classes, ODD, anxiety, depression, and addictions.

Most adults were involved in sports and clubs offered at their schools and were somewhat socially integrated. None of the participants, however, mentioned an activity or course that served to motivate them to persist in school - not even work experience programs. Six adults had participated in co-op placements and only Jason reported that he learned something from his 2month experience at a car dealership working "as a front-end mechanic and a tranny man." Guillaume explained why his short co-op placement in a restaurant was not useful:

I didn’t enjoy it because you didn’t feel like you were accomplishing anything. Two weeks are too short. You're given "joe" jobs, such as peeling potatoes and cleaning pots and floors because you're only there for such a short time. There was no real experience and not much training because you were only there for two weeks.

David commented, “Co-op was like a day off. We'd get coffee for the boss. I wasn't really learning anything. It was boring."

None of the participants mentioned career counseling in high school and their comments suggested that many of their parents did not have occupational expectations for them. Jake stated that his parents had no career expectations for him. He continued, "These people were in their own world. Career options for me weren't addressed." David made a similar comment: "They really didn't have any career expectations, they really didn't." Of the four participants whose parents did express hopes for their children, none had discussed or developed a plan to achieve career goals.

At the end of Grade 12, only Renata, Lorna, and David graduated within 4 years (see Table 3). However, Renata claimed she remembered little of her high school years because she was "doing alcohol and drugs," which may explain the results of recent testing showing that she needs upgrading in reading, writing, and math. Lorna graduated from an arts high school, but did not have a Grade 10 math credit required for admission into postsecondary institutions. David graduated from a vocational high school and did not have the academic requirements to do further studies at the college or university level. Jake, Guillaume, Liz, and Holly left high school and returned to either complete the remaining courses or obtain their GED. The other three (Cameron, Jason, and Tammy) dropped out of high school, and one was not even able to complete Grade 9.

In terms of postsecondary education, half of the participants enrolled in programs from non-accredited institutions. They received training in acting, performing ECG tests, massage therapy, digital media, and baking. All three adults who graduated from high school in 4 years 
Table 3

Academic Outcomes of Participants

\begin{tabular}{|c|c|c|c|}
\hline Participant & High School & Postsecondary & Other Comments \\
\hline Renata & Graduated & ECG training & $\begin{array}{l}\text { Did drugs and does not remember } \\
\text { most of it, needs upgrading }\end{array}$ \\
\hline Jake & Withdrew, obtained GED & $\begin{array}{l}\text { Drama courses, } \\
\text { some university }\end{array}$ & Behaviour problems in school \\
\hline Cameron & Withdrew from alternate high school & & $\begin{array}{l}\text { Does not have mandatory English, } \\
\text { math, or science courses }\end{array}$ \\
\hline David & $\begin{array}{l}\text { Graduated from a vocational high } \\
\text { school }\end{array}$ & Baking course & Needs upgrading \\
\hline Holly & Withdrew, obtained GED & & Needs upgrading \\
\hline Guillaume & $\begin{array}{l}\text { Withdrew from a vocational high } \\
\text { school, obtained a diploma from } \\
\text { adult high school }\end{array}$ & & Needs upgrading \\
\hline Jason & $\begin{array}{l}\text { Withdrew from a vocational high } \\
\text { school }\end{array}$ & & Found a 2-month co-op useful \\
\hline Liz & Withdrew, obtained GED & $\begin{array}{l}\text { Massage therapy } \\
\text { training, one } \\
\text { university course }\end{array}$ & $\begin{array}{l}\text { Severe anxiety contributed to her } \\
\text { withdrawal from high school }\end{array}$ \\
\hline Tammy & Has Grade 8 & $\begin{array}{l}\text { Digital media } \\
\text { training }\end{array}$ & $\begin{array}{l}\text { Failed } 3 \text { times in elementary } \\
\text { school }\end{array}$ \\
\hline Lorna & Graduated from an arts high school & & Does not have Grade 10 math \\
\hline
\end{tabular}

were among the five who took this type of training. None of the participants enrolled in a community college, and two adults took courses at the university level. Jake obtained his GED and was six credits short of his degree. He explained that written expression was a problem and his former girlfriend wrote his course papers. Unfortunately, their relationship did not last until he completed his program. Liz who also earned her GED took one university course in which the exams were in a multiple-choice format. However, she dropped her second course when she learned that the evaluation was exclusively essays; she explained that written expression was not her strength.

Half of the participants had enrolled in training programs for specific careers offered by private companies. However, they described situations where the programs did not lead to a job: there were no openings in the field in which they were training (e.g., ECG tester) or they did not have the academic qualifications (i.e., a high school diploma). Three participants had no postsecondary training, two did not graduate from high school (Jason attended a vocational high school and Cameron went to an alternative high school), and Guillaume attended a vocational high school before he withdrew and later returned to earn the required credits for a secondary diploma. Although Tammy only had Grade 8, she did take some postsecondary training, but this did not lead to employment because she lacked the basic qualification (i.e., a high school diploma).

When asked what schools could have done to provide a successful learning experience, most responded that a diagnosis, accommodations, and tools (e.g., assistive technology) to cope with their LD would have been useful. Three others mentioned that caring teachers and parents 
who recognized something was wrong and who advocated for a diagnosis and accommodations would have helped. Additionally, Renata and Holly commented that teachers who acknowledged their abilities instead of focusing only on their shortcomings would have contributed to their sense of accomplishment.

\section{Employment Experiences}

The participants had all held entry-level positions in the service sector that did not necessarily require a high school diploma, such as jobs in the food industry (fast food restaurants, server, bartender), retail (sales associate, pharmacy assistant, cashier), hotel sector (various departments at a resort hotel, chambermaid), general labour (carpentry, painting, masonry, laying sod, roofing, stevedore, babysitting), property management, and the armed forces. It appeared that most participants preferred jobs where it was not necessary to fill out an application form or provide proof of having a high school diploma. Liz, who left school and later obtained her GED revealed, "I never put down on the application that I don't have a high school diploma and they have never asked me for one."

Most of the participants stated that their previous educational experiences including coop placements were of little assistance in getting and keeping a job. Additionally, they admitted to being easily distracted, having a poor memory, or requiring individual training. However, two stated that their educational experiences were helpful. Lorna, who attended an arts high school said, "During interviews, I show proper body language and focus on being professional." Guillaume observed, "Having a high school diploma is definitely a bonus. The adult high school teaches you to be on time."

All of the participants enjoyed jobs in which they felt they could do well, were meaningful to them, and offered novelty. Guillaume had been in the military and stated, "It [the work] was hard, but I felt like I was doing something. Every day was something new-not the same old routine. There was always excitement and movement." The types of jobs the participants did not like were described as "boring." Lorna said that these jobs led to self-stimulation ("I start to hum when I am bored"), which led to trouble with her boss. The participants also did not like jobs in which they were not successful. David explained that he could not produce the same way or at the same rate as his co-workers and this resulted in reprimands from the boss. Liz also commented, "People are not always pleasant and you get yelled at a lot." Most of the participants stated that relations with their boss or co-workers were a problem. David reflected, "I loved every job. But I didn't like the people I was working with." Although the participants told of their problems with some jobs, none admitted to being let go by their employer. However, some revealed a spotty employment history: "I've been moving from one job to another" and "I work for three or four months." Three others stated that they had not worked for 11 months, a year, and 3 years.

All of the participants expressed a desire to work in an environment in which they were respected by others and at a job in which they were interested. David stated that he would like to "work with people who cared enough to realize that everyone is different. People make mistakes." Renata disclosed, "I need a patient, understanding boss who will repeat over and over again." Two other participants wished for "real paid jobs in areas of interest" (Tammy) and "something where I feel I'm accomplishing something" (Guillaume).

Despite the potential for difficulties with other staff and the risk of landing a boring job, all of the participants expressed a desire to work. Three were working at the time of their inter- 
views as a truck driver, telemarketer, and a swim coach (David, Holly, and Lorna, respectively). The remaining seven, however, were not looking for jobs: three had medical reasons (recuperating from an operation, two had depression), three wanted more training, and one was in school and could not manage a job and course work. More than half of the participants also revealed that from time to time they had given up looking for work. Guillaume, who had been in the army said, "I was actively looking for work and every door was slammed in my face." David observed, "At times it's depressing. You go to the employment centre and there's no phone call. A week goes by and there's no call. When you're on welfare, you have to go out and look for work." Renata commented that she was looking for employment "but my motivation is drained. I just go through a motivation drop when I feel frustrated." The remaining four adults claimed they had never given up looking for a job. Jason said, "Hopefully something will come up before I give up."

The participants' comments revealed the barriers they faced to getting a job: qualifications, transportation, and filling out the application forms. On his qualifications, Cameron said, "If I had finished high school and actually had mandatory English, math, and science courses that would help me [get a job]." Liz stated,

I have had fears and I have broken out in a sweat if there was a paragraph on the application about why I want the job. But it has not usually been a problem. Usually I can take the application home to work on it and get help with it. I use a dictionary to help me write.

They also experienced barriers to keeping a job: frustration, pressure, and relations with co-workers. Renata stated that she "usually ended up quitting due to frustration" because she needs a job coach to teach her the duties on a one-to-one basis. Jake said, "I work for 3 to 4 months. If there is pressure, then I move into flight." He defined "pressure" as "when I have to start writing or move to a more demanding job, then I become frustrated." Tammy cited problems with co-workers: "Getting along with people who I work with is a big barrier." She went on to explain, "There were misunderstandings. I always felt I needed to hide my learning disability. I couldn't keep up or produce the same as my co-workers."

Even though the participants were limited to entry-level jobs, six individuals had career goals: acting, museum technology, working with children in education, mechanic, and sound engineer. Of these participants, two were taking courses at the time of their interview. However, both of these people were faced with barriers to achieving their career goals: lack of money to enroll in more drama classes (Jake) and lack of a Grade 10 math credit to move into a teacher education program (Lorna). Renata and Tammy, who were both mothers of young children, did not have specific career objectives, but did have other goals that employment would bringfinancial independence and respect. They explained, "I want a job, a decent job, to be financially independent. I want my son to be proud of me" (Renata) and "I want my kids to see me as a hero" (Tammy).

Most of the adults recognized that in order to achieve their career goals they required further education. The idea of returning to school, however, was not appealing to most. Jason stated, "It's a little frustrating. I have lots of opportunities to do stuff, but it involves going back to school or doing stuff I'm not capable of." Others were concerned about the number of years further training would involve: "I don't know. It's lots of school. To be a sound engineer requires 2 to 3 years of school" (Cameron). In addition, some of the participants expressed a desire to get a job in order to get off welfare. However, in order to be considered for a job they needed more education, and going to school extended their time on welfare. Renata needed to do some up- 
grading and explained the dilemma: "I need one to two semesters at high school. If I go back to high school, I will have to stay on welfare. I want to get off welfare, to be normal, to be independent."

In addition to describing career goals and barriers to training, the participants also stated what they would need to be successful. They reported that a positive work environment and a supportive supervisor were absolutely necessary. Renata said that she needed a "patient boss, someone who is understanding... who can put themselves in my shoes...I need patient coworkers." Others commented, "An employer who is understanding and shows compassion" and "empathy and not 'What the hell's wrong with you?", Tammy stated that she wanted her boss to "understand that the frustrations, fears, sense of inabilities have all come from my learning experiences." Now that they knew they had LD, four of the women stated that they had no change in their attitude towards work, but that they would now consider different types of jobs. They now knew their weaknesses and would not apply for jobs that highlighted them.

\section{Personal Goals}

Most of the participants expressed the personal goal of achieving the financial security and better housing that a good job could provide. Jake was in his late thirties, lived at the "Y," and took drama classes when he could afford the tuition. He expressed that he would like "a bachelor apartment, a steady part-time job. I'd like to raise myself economically. At my age, I wouldn't mind having stability." Guillaume stated,

My biggest wish is to maintain a roof over my head, food in the fridge, and pay the bills. I'm not struggling. I want to stay out of that situation. I'd like to own a house one day, but that's a dream. You have to be realistic.

Still others expressed the peace of mind that having a job could bring: "I would eventually like to end up in a job that I am content with and where I feel I am making a difference. I would like to stay healthy and happy," stated Liz.

The participants' comments indicated that personal goals were linked with a better job and most indicated that they needed more education to attain their career goals. However, only three expressed a desire to return to school. Cameron had dropped out of an alternate school and felt that a diagnosis of LD might provide a better chance at going to college: "I'm feeling hopeful. I was feeling depressed. There is a chance now I can get into school. I feel less stupid, less like it's my fault." He added, "I'd like to go to school and keep focused. I don't know." The last sentence expresses the doubt that many of the participants had with respect to returning to school to upgrade their education. Some were also faced with the dilemma of continuing their education or working. David who had been employed as a truck driver said, "This job is stopping me from doing other things [obtaining training]. But it gives me self-esteem." Education would be helpful to reach long-term goals, but some of the participants felt they needed to focus on their present needs.

\section{Sources of Moral Support}

While in high school, five participants stated that their families provided moral support and helped them with their homework. Liz, who showed symptoms of anxiety in high school, 
stated that her parents advocated for her. She was the only participant who indicated that her parents engaged in advocacy; however, two others wished their parents had requested testing and accommodations. Five individuals commented that while in school their parents were not supportive. Renata said, "It was me, my brother, and my sister. There were no adults. We protected each other from my mom and dad." Tammy said of her mother, "She is an alcoholic and she was in an accident and had head injuries when I was a kid. So I didn't have much support."

The comments of seven participants also indicated that most teachers paid little attention to them: "I fell through the cracks in high school," "I was pushed aside," and "I felt that they swept me under the carpet." Renata stated that her difficult behaviour at school was a cry for help, to which there was no response from her teachers. She furthered, "They would rather give me a detention than ask why." Tammy said, "I wasn't understood or given a chance from many of my teachers. If [they] knew how to help me it would have made a huge difference in my life."

Now that they were out of school, only six stated that they felt supported by family members, professionals (e.g., psychologist, social worker, Learning Disability Association), or their faith. Four of the participants reported that they had no sources of support. David poignantly expressed,

I would like to have guidance from someone... someone who was knowledgeable and could teach you. You've got four billion people in the world. I still feel alone. I always felt that way...I've always had people take advantage of me. Even my own family. It's hard to find a person who can be real and accept me as I am. I always feel as though I'm in a hole and I'm trying to get out. I don't feel anyone would help me succeed.

\section{Fear: Education, Employment, and Having a Learning Disability}

A theme that emerged from the interview data was the fear the participants related to their LD: being "found out," on-the-job training and making mistakes, and returning to school. Tammy spoke of hiding her LD and the effects it had on her:

I have emotional issues due to the fact that I hid the fact that I can't write or spell for 15 years. It was just last year that I was able to admit that...I have been sick with depression, anxiety attacks, and social phobias. I have withdrawn and have not participated in society for the past three years because I am anxious about how I would compete without a diploma.

On having to reveal LD, Renata said, "You don't want to tell them that you have a learning disability. But when they notice things, you have to tell them and it's like you're being dishonest."

On-the-job training posed problems in terms of following instructions. David said, "I feel a lot of pressure. I know reading comprehension is a problem. Instructions - I can't remember them. I always carry a pad and pen. I have to write things down...I need repetition [of instructions]." Some participants were also afraid of making mistakes on the job. Tammy explained, "My LD is my biggest barrier. I process things the wrong way sometimes, like I read things wrong. I forget things and have a bad memory." Hence, the deficits that caused them problems at school also caused difficulties during the training phase of a new job.

Participants also expressed fears about obtaining more education. Renata said, "I need upgrading. I don't want to do high school again. I don't want to go back to high school. It wasn't a pleasant experience the first time. I guess that's why I fear it a bit." Jason stated, "Me and the classrooms just don't get along.... Unless I have someone there to read it to me, after four sen- 
tences, it's just words to me." Liz, who withdrew and has her GED said, "It is hard to build confidence after so many negative experiences at school. Part of me still doubts that I am capable of doing it."

\section{Thoughts on How Having an Undetected Learning Disability Had Affected Their Lives}

The participants commented on the effects of having LD that was undiagnosed during elementary and secondary school. Some of the statements revealed concerns about self-esteem. Renata said, "If I would have gotten the help I needed, I wouldn't have felt like such a failure.... It would have helped with my self-esteem a lot if I could have had the tutoring help." Lorna commented,

If I was diagnosed earlier I would not have had low self-esteem. If I had known what my problems were and how to get help for them, it would have helped my social skills....Also feeling behind my peers for 16 years contributed to poor mental health.

Others felt that if they had received help with their LD while in school, they would have had better career outcomes now. Tammy said, "I would probably have a successful career right now if I could have graduated from high school." Lorna stated that if she had received a diagnosis and assistance while in school "[she] would have been on track earlier to getting my life together." There appeared to be a feeling among some of the participants that having an undetected LD contributed to poor self-esteem and delays in finding a career path.

\section{Discussion}

This study examined the educational and work experiences of adults recently identified as having LD as adults. The essence of their educational and employment experiences was developed from the findings.

\section{Educational Experiences}

While in elementary school some type of academic assistance may or may not have been provided. However, no formal identification procedures were undertaken. This is possibly because their families moved frequently or their parents were preoccupied with their own issues. It also seemed that teachers tended to overlook these at-risk students because their parents did not advocate for them. By the time the participants were in high school, behavioural problems and secondary disabilities had emerged. Additionally, most of them were not enrolled in academic level courses and were not developing skills in reading, written expression, or math that would serve them in future studies or employment. As well, they did not have a clear sense of their strengths and weaknesses and had not developed coping and self-advocacy skills. In addition, unlike the participants in the Litner et al. (2005) study, there did not appear to be anything at school to keep them engaged and most did not leave with a high school diploma. Although some had co-op experiences in high school, they were not generally deemed to be helpful in regard to identifying a career goal and the steps to reach it. 
Although seven participants eventually obtained a high school diploma or the equivalent, none had developed the academic and metacognitive skills, obtained the prerequisite courses, or had the sustained motivation to complete a university program. Interestingly, none of the adults seemed to have considered programs offered at the community college level. Most sought shortterm training programs provided by private firms as a means of upgrading their limited qualifications - programs that did not lead to permanent employment.

\section{Employment Experiences}

All of the participants had held a range of entry-level jobs that did not necessarily require a high school diploma, which supports the results of previous studies (Blackorby \& Wagner, 1996; Mellard, 1996). Some individuals expressed difficulties with the training phase of the job because their LD made it difficult for them to remember the tasks unless they had individual training with lots of repetition. Once in the job, it appeared that the participants did not want to disclose their deficiencies and their employers were not prepared for employees who needed accommodations (Lindstrom et al., 2007; Price \& Gerber, 2001; Price et al., 2003). As a result, most experienced some conflict with the boss and co-workers over job performance, which again appeared to be linked to their LD. When there were problems on the job and the supervisor admonished them, some of the participants stated that they responded impulsively and angrily. In some cases, the pressure and frustrations resulted in them quitting their jobs, which for some adults led to depression. After awhile, many months in some cases, they were ready to try working again and the cycle began anew. However, it was difficult to maintain a strong sense of motivation when they could not find a job. The participants in this study appeared to have been in a prolonged "unsettled" stage as described by Lindstrom and Benz (2002).

Although the participants all had dreams about the types of jobs they would like to have, the reality was that they did not have specific career goals. It has been shown that having a career goal is an important first step toward embarking on a career path (Lent, Hackett, \& Brown, 1999; Lindstrom \& Benz, 2002; Werner \& Smith, 2001). Most recognized that to obtain a higher status job they would need to improve their academic qualifications. However, few seemed motivated to return to school to take upgrading courses and enroll in programs that would provide the education required to reach their goals. Some explained that they were not capable of succeeding in higher education, others expressed that returning to school would be distressing due to painful memories, and others stated that financially they could not manage it. While some said that they wanted to get off welfare, doing so meant risking self-esteem by re-engaging in academicssomething they feared would lead to further failure. And further failure eroded their sense of personal determination to achieve their goals.

\section{The Effect of Learning Disabilities on Academic and Employment Experiences}

The participants felt that having an undiagnosed LD affected their academic achievement, social skills, and present career outcomes. They perceived that if an adult had advocated on their behalf for testing, they would likely have been diagnosed while in school and could have received accommodations, which would have helped them pass courses and obtain a diploma. Some individuals seemed to equate having a high school diploma with a "successful career." However, seven participants did have a high school diploma or the equivalent, but it did not lead 
to a successful career. Even though they had the "piece of paper," there were abilities and skills that they were lacking. While in school they needed to have had their parents or another adult monitor the development of academic skills, such as reading comprehension, written expression, and math. The participants also would have benefited from the opportunity to learn specific life skills (e.g., self-advocacy and personal learning strategies) that may be applied to a range of training/educational contexts. They also needed to have an understanding of their strengths and weaknesses and how to execute executive functions (time management, metacognition, setting work priorities). Additionally, these adults should have developed strong interpersonal skills and the personal qualities of determination and motivation that are sustained until a goal is reached. As well, the participants would have benefited from parents and teachers who helped them set career goals and develop a plan to reach them that included appropriate vocational experiences and enrollment in the prerequisite courses (Lindstrom et al., 2007).

Unlike the participants in the Werner and Smith (2001) study, these adults did not have parents and teachers who were prepared to nurture and mentor them. Additionally, no one advocated for an assessment while they were in elementary or secondary school. Consequently, they missed the opportunity to understand their LD and how to manage it so that they could find environments that fit their strengths. They were also denied the chance to develop skills that could be transferred to both postsecondary studies and employment. More than that, they missed opportunities to experience success and develop self-esteem and self-determination. It was as though they had come as far as they could possibly go without these skills, abilities, and attitudes.

\section{Will Having a Diagnosis Make a Difference in Their Lives Now?}

While the question cannot be answered with complete certainty, Bandura's (1986) general social cognitive theory provides some clues as to how their lives may unfold. General social cognitive theory involves the interplay of three variables. First, self-efficacy-confidence in one's ability to successfully perform a given task or set of tasks - helps determine whether an individual will initiate, persevere, and succeed at particular endeavours. The elements that contribute to self-efficacy are gender, race/ethnicity, disability/health status, and other personal characteristics and genetic predispositions. The strongest source of self-efficacy, however, is successful performance. Second, outcome expectations are the expected consequences of performance. Bandura stated that both types of beliefs-expected performance on a task and expected outcomes of performance - are related. For example, people may anticipate doing poorly academically in high school courses and may not persist, particularly if they see no positive outcomes in having a high school diploma. Third, goals refers to one's determination to engage in a given activity or to affect a particular outcome (Bandura, 1986). To illustrate, an individual's determination affects whether or not he or she will complete a difficult high school course, graduate and enter a postsecondary program, or get a particular job. Goal-setting contributes to the strength of determination and guides personal, educational, and vocational behaviour.

Social cognitive theory may also offer some explanation as to why these participants were reluctant to return to school to obtain academic qualifications that would lead to postsecondary education and a career path. They had experienced failure while in high school and their academic self-efficacy was low. Due to their undiagnosed LD and previous negative experiences, they showed little initiative and held low expectations for success at academic tasks. As well, none of the participants indicated a belief that obtaining a high school diploma or upgrading their academic skills would lead to a better occupation. Therefore, there seemed to be a tacit under- 
standing that going back to high school was not going to make a significant difference in their lives. They would still be applying for entry-level jobs and likely losing them because of their LD and their poor problem-solving and interpersonal skills. Moreover, none of the participants expressed the strength of determination that would support them through difficult times if they were to enroll in postsecondary education. Additionally, few participants had specific career goals that could be translated into a series of actions, academic and metacognitive skills, and support networks that would contribute later to a smooth school-to-work transition (Lent et al., 1999).

Instead, participants took entry-level jobs or training courses that did not lead to a productive career path. Their comments suggested that they perceived that they were at the mercy of the environment to provide an emotionally safe work situation for them, as they had no mentor or people in their lives who could provide career guidance and support. As David said, it was like being on "pause," not moving forward in their lives. They appeared to feel that they were trapped in a negative employment cycle and did not have the individual characteristics or a supportive environment to return to school and restart their lives in a new direction. Unfortunately, participants' comments did not offer much hope that a diagnosis at this time would make much difference in the course of their lives. However, what might make a difference is the availability of career counseling, training in job social skills and problem-solving, and a mentor who would provide advice and support over an extended period of time.

\section{Limitations}

One of the limitations of this research was the small number of participants. There was not a deep pool of adults who had recently been diagnosed with a LD upon which to draw. However, working closely with provincial and local offices of associations for LD and posting the recruitment notice on provincial websites might increase the number of participants. It also seemed that the participants limited what they told us. They tended to minimize their negative characteristics, such as poor interpersonal skills, and point to others for their lack of success, particularly in the workplace. Another limitation was that a single source of data was used. An individual interview was chosen over a questionnaire because of the reading and writing difficulties of the participants. As well, it was felt that the participants may not have been able to meet the commitment involved in a series of interviews. However, perhaps some of these limitations might be addressed by using Seidman's (2006) three-interview method to provide more opportunity to check for internal consistency. Despite these limitations, it is felt that there were sufficient data to permit the researchers to understand how the participants made meaning of their experiences and for the readers to make generalizations to their own situations.

\section{Implications}

The findings of this study add to our understanding of LD by describing the meaning individuals with recently identified LD make of their educational and post-school experiences. An important finding was that the participants felt that they were not assessed early enough to give them the opportunity to learn important academic and employment skills and for them to experience success (Lerner, 2000; Wong, 1996). It should be noted, however, that a diagnosis alone does not lead automatically and in itself to positive outcomes (Werner \& Smith, 2001). Using a 
risk and resilience framework, there are several factors that have bi-directional influences across multiple contexts, and having a diagnosis of LD is one of those factors. Wong (2003) explained that within the factor of LD, there are two other considerations (gender and severity) that affect how this factor will play out over a lifetime. A third consideration emerging from this study may be the additional presence of ADHD and/or mental health problems (anxiety and depression). Future longitudinal research may provide further information about the dimensions of the LD risk factor.

The findings also suggest several implications for student outcomes, policy, and practice. Over the course of their elementary and secondary education, at-risk students and those with LD should develop a range of individual characteristics: academic skills (reading, writing, and math), personal learning skills, an understanding of their strengths and weaknesses, selfadvocacy skills, executive skills, persistence, and determination. These skills are critical for school success and may later be transferred to a job setting. Additionally, these students should develop strong interpersonal skills in order to help build a supportive environment.

Based on the findings of this study, policies in the area of career identification and development should be established in high schools to assist students in determining realistic employment goals and mapping out paths that may include pre-requisite courses and vocational training. High school students should also be assigned mentors who will nurture a sense of selfesteem and oversee that these steps are taken, particularly for those with disabilities or who are at-risk. When they leave high school, assistance in finding job opportunities would also benefit the students to make a smooth transition to the workplace. Throughout their schooling, these students also need access to supportive adults and peers who will foster a sense of self-esteem, especially when they are feeling discouraged.

Most importantly, teachers need to advocate for the needs of at-risk students, particularly when their parents are not able to do so. All students need caring teachers who will help them experience success, which in the long-term would contribute to a sense of self-efficacy and control over their lives. With these recommendations in place, it is possible that students with undetected LD will be identified and recover from their at-risk status, such as occurred with the cohort studied by Werner and Smith (2001).

Does having LD mean that a person will always be "mediocre"? Not necessarily. Studies have shown that individuals with LD can be successful (Fullarton, 2006; Gerber et al., 1992; Lindstrom \& Benz, 2002; Werner \& Smith, 2001). However, without a diagnosis and the careful attention of teachers and parents, some students with LD will be denied success and a sense of achievement, and as adults will feel "paused" as they struggle to make their way in life.

\section{References}

Bandura, A. (1986). Social foundations of thought and action: A social cognitive theory. Englewood Cliffs, NJ: Prentice-Hall.

Blackorby, J., \& Wagner, M. (1996). Longitudinal post-school outcomes of youth with disabilities: Findings from the National Longitudinal Transition Study. Exceptional Children, 62, 399-413.

Denzin, N., \& Lincoln, Y. (Eds.). (2000). Handbook of qualitative research (2nd ed.). Thousand Oaks, CA: Sage.

Duquette, C. (2000). Examining autobiographical influences on student teachers with disabilities. Teachers and Teaching: Theory and Practice, 6, 215-228. 
Fourqurean, J., Meisgeir, C., Swank, P., \& Williams, R. (1991). Correlates of postsecondary employment outcomes for young adults with learning disabilities. Journal of Learning Disabilities, 24, 400405.

Freeman, M., deMarrais, K., Preissle, J., Roulston, K., \& St. Pierre, E. (2007). Standards of evidence in qualitative research: An incitement to discourse. Educational Researcher, 36(1), 25-32.

Friend, M., Bursuck, W., \& Hutchinson, N. L. (1998). Including exceptional students: A practical guide for classroom teachers, Canadian edition. Scarborough, ON: Allyn \& Bacon.

Fullarton, S. (2006, May). Postsecondary school outcomes for students with learning disabilities. Paper presented at the $75^{\text {th }}$ Congress of the Humanities and Social Sciences, Toronto, ON.

Gerber, P., Ginsberg, R., \& Reiff, H. (1992). Identifying alterable patterns in employment success for highly successful adults with learning disabilities. Journal of Learning Disabilities, 25, 475-487.

Guba, E., \& Lincoln, Y. (1989). Fourth generation evaluation. Newbury Park, CA: Sage.

Halpern, A., Yovanoff, P., Doren, B., \& Benz, M. (1995). Predicting participation in postsecondary education for school leavers with disabilities. Exceptional Children, 62, 151-164.

Hutchinson, N. L. (2007). Inclusion of exceptional learners in Canadian schools: A practical handbook for teachers (2nd ed.). Toronto, ON: Pearson Prentice Hall.

Learning Disabilities Association of Canada. (2002). LDAC definition of learning disabilities. Ottawa, ON: Author.

Lent, R., Hackett, G., \& Brown, S. (1999). A social cognitive view of school-to-work transition. The Career Development Quarterly, 47, 297-311.

Lerner, J. (2000). Learning disabilities (8th ed.). Boston: Houghton Mifflin Company.

Lindstrom, L., \& Benz, M. (2002). Phases of career development: Case studies of young women with learning disabilities. Exceptional Children, 69, 67-83.

Lindstrom, L., Doran, B., Metheny, J., Johnson, P., \& Zanc, C. (2007). Transition to employment: Role of the family in career development. Exceptional Children, 73, 348-366.

Litner, B., Mann-Feder, V., \& Guérard, G. (2005). Narratives of success: Learning disabled students in university. Exceptionality Education Canada, 15(1), 9-24.

Marshall, C., \& Rossman, G. (2006). Designing qualitative research (4th ed.). Thousand Oaks, CA: Sage.

Mellard, D. (1996). Strategies for transition to postsecondary educational settings. In D. D. Deshler, E. E. Ellis, \& B. K. Lenz (Eds.), Teaching adolescents with learning disabilities (2nd ed., pp. 475-523). Denver, CO: Love Publishing Company.

Mertens, D. (2005). Research and evaluation in education and psychology (2nd ed.). Thousand Oaks, CA: Sage.

Miles, M., \& Huberman, A. (1994). Qualitative data analysis (2nd ed.). Newbury Park, CA: Sage.

Moustakas, C. (1994). Phenomenological research methods. Thousand Oaks, CA: Sage.

Patton, M. Q. (1990). Qualitative evaluation and research methods. Newbury Park, CA: Sage.

Patton, M. Q. (2002). Qualitative research \& evaluation methods. Thousand Oaks, CA: Sage.

Pinar, W., \& Grumet, M. (1976). Toward a poor curriculum. Dubuque, IA: Kendall/Hunt.

Price, L., \& Gerber, P. (2001). At second glance: Employers and employees with learning disabilities. Journal of Learning Disabilities, 34, 202-210.

Price, L., Gerber, P., \& Mulligan, R. (2003). The Americans with Disabilities Act and adults with learning disabilities as employees: Realities of the workplace. Remedial and Special Education, 24, 350-358.

Raskind, M., Goldberg, R., Higgins, E., \& Herman, K. (1999). Patterns of change and predictors of success in individuals with learning disabilities: Results from a twenty-year longitudinal study. Learning Disabilities Research and Practice, 14, 35-49.

Reis, S., Neu, T., \& McGuire, J. (1997). Case studies of high-ability students with learning disabilities who have achieved. Exceptional Children, 63, 463-479.

Rojewski, J. (1999). The role of chance in the career development of individuals with learning disabilities. Learning Disability Quarterly, 22, 267-278.

Seidman, I. (2006). Interviewing as qualitative research (3rd ed.). New York: Teachers College Press. 
Werner, E., \& Smith, R. (2001). Journeys from childhood to midlife: Risk, resilience, and recovery. Ithaca, NY: Cornell University Press.

Wong, B. (1996). The ABCs of learning disabilities. San Diego, CA: Academic Press, Inc.

Wong, B. (2003). General and specific issues for researchers' considerations in applying the risk and resilience framework to the social domain of learning disabilities. Learning Disabilities Research \& Practice, 18, 68-76.

\section{Authors' Note}

Correspondence concerning this article should be addressed to Cheryll Duquette, University of Ottawa, Faculty of Education, 145 Jean Jacques Lussier, Ottawa, ON K1N 6N5.

Email: cduquett@uottawa.ca

\section{Appendix}

\section{Adults with Learning Disabilities: Individual Interview Questions}

Demographic

1. What is your age?

2. Are you married or single?

3. Have you ever been married?

4. Do you have any health problems that would restrict your employment opportunities? Do you have a criminal record?

5. What type of learning disability have you been diagnosed as having?

6. What does having a learning disability mean for you?

7. How do you feel about having a learning disability?

8. Have you ever suspected that you might have a learning disability? If so, tell me about it.

Schooling Experience

9. Tell me about your elementary school experiences.

10. Tell me about your secondary school experiences.

11. What was hard or did not like at school? What was easy or liked?

12. Did you participate in extracurricular activities or sports? If so, what?

13. What type of academic assistance did you receive in school, for example going to the resource teacher or being in a special class?

14. Did you participate in a coop program at high school?

15. Did you graduate from high school?

16. Did you do any postsecondary training? If so, where and what type of course? Did you graduate? Did you expect that the training would lead to a job?

17. What would have been a successful school experience for you?

Work Experience

18. While in high school did you have part time jobs? If so, what were they? Available?

19. Were you ever let go or quit? If so, why?

20. What jobs have you held since high school?

21. Were you ever let go or quit? If so, why? 
22. Tell about the job you enjoyed the most. Why did you enjoy it?

23. Tell about the job you did not enjoy at all. Why did you not enjoy it?

24. What would be a successful work experience for you? (For example, is there something the boss can do for you?)

25. Do you want to work?

26. Do you look for work?

27. Why are you not working now? How long have you been out of work?

28. Have you ever given up on finding work? If so, why? (Loss of confidence?)

29. What type of job would you like? What do you think you are good at doing?

30. Do you need training? If so, what would it be and where can you get it?

31. What are the barriers to getting training? How do you get around these barriers?

32. What are the barriers to getting a job? (For example, filling out application forms)

33. Is there something other than training you would need to be employed? If so, what is it? (For example, a job coach, someone to drive you to and from work, sheltered workshop, someone to help me find a job)

34. What are the barriers to keeping a job? How do you get around these barriers?

35. What type of support can employers give you?

36. How could your educational experiences have helped you get a job?

Housing

37. For single adults: Are you living by yourself, with friends, or with your parents?

For married adults: Are you living with your husband/wife? Do you have children? If so, tell me about them (age, gender, etc.)

38. Have you ever been homeless? If so, in what city and for how long?

39. What are your housing needs? (For example, subsidised or supervised.)

Personality Traits

40. What are your best personality traits/characteristics? (For example, able to come up with other ways to solve problems, hard worker, determined, persistent)

41. What are your worst personality traits/characteristics? (For example, disorganized, poor memory, impulsive, don't get along with others)

42. What do you do to cope with them? How did you learn these coping strategies?

Moral Support

43. Who provides you with moral and active support now? (For example, to keep up your confidence)

44. When you were in school, who provided moral support for you? (Adult role models)

45. What career expectations did your parents have for you?

46. Are your friends working? If so, what are they doing?

47. Do you have trouble making friends?

48. Do you have trouble keeping friends?

Reflections

49. If you had known while you were in school that you had a learning disability, would things be any different now?

50. What type of program or special assistance might have helped? (For example, resource teacher, coop program, nothing could have helped)

51. Now that you know you have a learning disability, will that affect your attitude towards working? If so, how?

52. How would you have liked your life to turn out so far?

53. What are/were your long term goals? Short term goals?

54. How do you feel about the ways things in your life are going?

55. How can you make things better?

56. Do you think you will take these steps?

57. Is there anything you would like to say about your learning disability, your educational experiences, your work experiences or anything else? 